\title{
IMPLEMENTASI JAMINAN KESEHATAN NASIONAL (JKN) \\ DI KABUPATEN BUOL
}

\section{IMPLEMENTATION OF THE NATIONAL HEALTH INSURANCE IN BUOL REGENCY}

\author{
Saharudin Is Lamadangl, Amran Razak², Syamsiar Russeng² \\ ${ }^{1}$ Bagian AKK, Fakultas Kesehatan Masyarakat, Universitas Hasanuddin Makassar, \\ ${ }^{2}$ Bagian Keselamatan dan Kesehatan Kerja, Fakultas Kesehatan Masyarakat, \\ Universitas Hasanuddin, Makassar
}

\begin{abstract}
Alamat Korespondensi: Fakultas Kesehatan Masyarakat Universitas Hasanuddin, Makassar, 90242 HP:+6285299222907, Email: erlina_hb@yahoo.com
\end{abstract}

\begin{abstract}
Abstrak
Pemerintah bertanggung jawab atas pelaksanaan jaminan kesehatan masyarakat melalui sistem Jaminan Sosial Nasional dengan sasaran masyarakat Penerima Bantuan Iuran.Tujuan penelitian ini mengkaji Implementasi Jaminan Kesehatan Nasional di Kabupaten Buol.Rancangan penelitian yang digunakan penelitian kualitatif pendekatan studi kasus dengan desain kasus tunggal menggunakan teori Implementasi, data diperoleh melalui informan dengan prosedur Purposive sampling yang berada di Dinas Kesehatan, BPJS, Dinas Sosial, Kepala Desa, Kepala Puskesmas dan staf serta masyarakat sebagai sasaran Jaminan Kesehatan Nasional, teknik pengumpulan data dengan dokumen, wawancara serta observasi._Regulasi yang telah dibuat namun tujuan regulasi belum tercapai, perbedaan data kepesertaan, kriteria dalam menentukan kepesertaan, Kurangnya tenaga kesehatan di puskesmas masih menjadi kendala utama dalam proses Implementasi. Komunikasi, koordinasi dan sosialisasi, karateristik organisasi yang berbeda sala satu penghambat proses implementasi sehingga Luaran Kinerja Implementasi masih menyimpang dari masyarakat yang bukan menjadi sasaran Penerima Bantuan Iuran Jaminan Kesehatan Nasional.

Katakunci: Implementasi, Jaminan Kesehatan Nasional

\section{Abstract}

Govermment is responsible for the implementation of Public Health Insurance trough the National Social Security System that targets commnuities contribution recipient . the puspose of this study examines the Implementatation of the National Helath Insurance System In Buol.The research design used qualitatif research case study approach with a single case design using the theory implementation, the data where obatained by the informant with the procedure purposive sampling that is the Department of Health, BPJS, Social Services, the village chief, the head of the health center and the staff and staff and the community as a target of the National Health Insurance Sytem, data collection techniques with documents, interview and observation. The research, found that regulation has been drafted but not yet achieved regulatory purposes, the difference in membership data, the criteria in determining membership, lack of health workers in health center are still major obtacles to the implementation process.Communication, coordination and disermnination, organizationof different characteristics are of the obstacle of the implementation process so that they deviate outcomes implementation performance of the public who are not the target of the recipient of the National Health Insurance Contribution
\end{abstract}

Keywords: Implementation, National Health Insurance. 


\section{PENDAHULUAN}

Pemerintah bertanggung jawab atas pelaksanaan jaminan kesehatan masyarakat melalui sistem Jaminan Sosial Nasional Tentang Optimalisasi Program Jaminan Kesehatan Nasional kepada pemerintah daerah agar mengalokasikan anggaran dalam rangka pelaksanaan Program Jaminan Kesehatan Nasional , memastikan seluruh penduduknya terdaftar dalam Program Jaminan Kesehatan Nasional serta menyediakan sarana dan prasarana pelayanan kesehatan sesuai standar kesehatan dan sumber daya manusia kesehatan yang berkualitas di wilayahnya masing-masing.

Penelitian dilakukan oleh oleh Rukmini dkk (2017) masalah peserta PBI APBD yang belum mempunyai NIK, Validitas kepesertaan masyarakat yang memenuhi kriteria miskin. Dinamika data, perubahan jumlah peserta karena meninggal, keluar kepesertaan, pindah atau sudah mampu Kesulitan pendistribusi kartu karena data dari BPJS, hanya ada nama dan alamat faskes, tidak ada alamat peserta, Keterlibatan Dinsos untuk validasi dan verifikasi kepesertaan PBI APBN. (Rukmini, dkk. 2017), demikian juga penelitian yang dilakukan oleh setyawati dan suryawati (2016) bahwa aspek kepesertaan belum dilakukan validasi terhadap peserta program PBI APBD masyarakat miskin, aspek pelayanan kesehatan: pelayanan di fasilitas kesehatan belum optimal, belum seluruh masyarakat memahami prosedur pelayanan kesehatan, aspek pembiayaan: Anggaran Pendapatan dan Belanja Daerah belum mencukupi (Setyawati,dkk. 2016) demikian juga penelitian yang dilakukan oleh Maidin Alimin dan Paluturi (2016) bahwa masalah yang berkaitan dengan aspek kebijakan dan kelembagaan, transformasi program, advokasi dan sosialisasi program JKN, kepesertaan, infrastruktur pelayanan pada fasilitas kesehatan, system rujukan dan Sumber Daya Manusia (Maidin \& Palutturi, 2016).

Pelaksanaan Jaminan Kesehatan
Nasional belum maksimal baik ditinjau dari kepesertaan, regulasi, dan fasilitas kesehatan maupun proses implementasi permasalahan ini timbul dari hasil pengamatan penulis dan penelitian terdahulu yang telah dilakukan terhadap Implementasi Jaminan Kesehatan Nasional.

\section{METODE PENELITIAN}

\section{Lokasi penelitian}

Lokasi penelitian dilaksanakan di Kabupaten Buol propinsi Sulawesi Tengah meliputi Dinas Kesehatan Kabupaten Buol, BPJS Kab. Buol, Dinas Sosial Kab. Buol, Dinas PPKAD, Para Kepala Desa di Kecamatan Momunu, Gadung, Lakea. Masyarakat Peserta Penerima Bantuan Iuran di Kecamatan Momunu, Lakea, Gadung dan Puskesmas Momunu, Gadung, Lakea, dilaksanakan Bulan Maret s/d Mei 2018.

\section{Rancangan penelitian}

Rancangan penelitian yang digunakan adalah Penelitian Kualitatif guna mengkaji Implementasi Jaminan Kesehatan Nasional secara intensif, terinci dan mendalam tentang kegiatan, sasaran, proses dalam kelompok orang, lembaga, atau organisasi (Yin, 2008) dengan pendekatan studi kasus (Case Study). Desain penelitian ini adalah kasus tunggal yang menggunakan teori Implementasi. Van Meter, D. S., \& Van Horn, C. E. (1975)

\section{Teknik pengambilan sampel}

Teknik pengambilan sampel (Social Situasion) peneliti mengamati secara mendalam aktivitas (aktiviti) orang-orang (Acktor) yang ada pada tempat (Place) dan melakukan pengumpulan data melalui 12 (dua belas) informan dengan prosedur Purposive sampling karena informan tersebut terlibat langsung dengan Proses Implementasi Jaminan Kesehatan Nasional diharapkan dapat memberikan informasi jelas dan terpercaya.

\section{Pengumpulan data dan Analisis data}

Bentuk pengumpulan data dengan dokumen, observasi dan wawancara mendalam kemudian peneliti melakukan 
Triagulasi data sekaligus menguji kredibilitas dan dilakukan Analisis Data meliputi Reduksi Data, Penyajian Data dan Penarikan kesimpulan penelitian.

\section{HASIL PENELITIAN}

Standar Kebijakan dan Sumber Daya Jaminan Kesehatan Nasional di Kabupaten Buol dari hasil penelitian meliputi Aspek Peraturan/regulasiRegulasi yang dikeluarkan pemerintah Kabupaten Buol maupun Regulasi dari kementerian yang menjadi dasar pelaksanaan pelayanan Kesehatan di tingkat FKTP. Regulasi dikeluarkan oleh pemerintah Kabupaten maupun yang bekerjasama dengan BPJS dalam pelaksanaan Jaminan Kesehatan Nasional di Kabupaten Buol meliputi SK Bupati Buol tentang pelayanan program Jamkesda bagi rumah tangga miskin dan orang tidak mampu penerima bantuan iuran PBI, Perjanjian Kerjasama antara Pemda Buol dan BPJS, SK BPJS Kepala Divisi Regional tentang forum komunikasi serta Peraturan Bupati Buol tentang Alokasi Dana Kapitasi JKN di Puskesmas.

Aspek Kepesertaan adalah Penerima Bantuan Iuran PBI APBN dan PBI APBD Jaminan Kesehatan Nasional meliputi orang yang tergolong fakir miskin dan orang tidak mampu.Penetapan penerima Bantuan iuran Jaminan Kesehatan Masyarakat (PBI APBN) berdasarkan keputusan kementerian sosial pada tahun 2016 di Kabupaten Buol sebanyak 64,477

Peserta, tahun 2017 terjadi 4 (empat) kali perubahan kepesertaan PBI APBN dengan jumlah peserta 66,724 dan berdasarkan data BPJS jumlah peserta PBI APBN yang terdaftar dalam Jaminan Kesehatan Nasional di Kabupaten Buol sampai dengan bulan maret 2018 sebanyak 60.695Hasil wawancara dengan informan sebagai berikut ;

Verifikasi kepesertaan PBI APBN dan PBI APBD sebagai berikut:

“.....kalau peserta Jamkesda (PBI $A P B D)$ tidak terlalu susah dalam memverifikasi, kita lihat kartu KK Kalau Pekerjaan Wirasusta kita tidak masukan ke Peserta Jamkesda kalau pekerjaan Petani dan Nelayan kita masukan ke Jamkesda .....Peserta PBI APBN kita telusuri melalui kartu KK diberi keterangan peserta yang meniggal, pindah...." (Informan SLT).

Penggantian Kepesertaan berdasarkan Musyawarah desa

kita telah laksanakan Mudes, nama-nama yang diganti kita usulkan namun tapi tidak ada perubahan nama yang keluar..." (Informan,JSM).

Pendistribusian kartu Kepesertaan JKNKIS

“...distribusi kartu itu kita memakai pihak ketiga...bekerjsama di dengan Dinas Sosial untuk pendistribusian kartu ." (Informan BS).

Hasil wawancara disimpulkan bahwa Verifikasi kepesesytamaPaI APBA\$alan Pdah pendistribusian telah dilaksanakan.

Aspek pembiayaan yang dikeluarkan oleh pemerintah daerah (APBD) dalam membiaya kepesertaan serta menunjang pelaksanaan Jaminan Kesehatan Nasional, Pembiayaan kepesertaan PBI APBD Kabupaten Buol Tahun 2017 sebagaimana yang tertuang dalam perjajian kerjasama antara Pemerintah Daerah Kabupaten Buol dan BPJS total pembiayaan sebanyak Rp. 2.431.008.000 (dua milyar empat ratus tiga puluh satu juta delapan ribuh rupiah) dan pada tahun 2018 pembiyaan dikeluarkan sebanyak Rp. 8.724.636.000 (delapan Milyar tuju ratus dua puluh empat enam ratus tiga puluh enam ribuh rupiah).

Aspek Pelayanan Kesehatan di FKTP mengenai keadaan tenaga, Prasarana dan Sarana dan pelaksana P-Care di Puskesmas dari hasil wawancara dengan informan sebagai berikut ;

Jumlah dan Kualifikasi tenaga kesehatan 


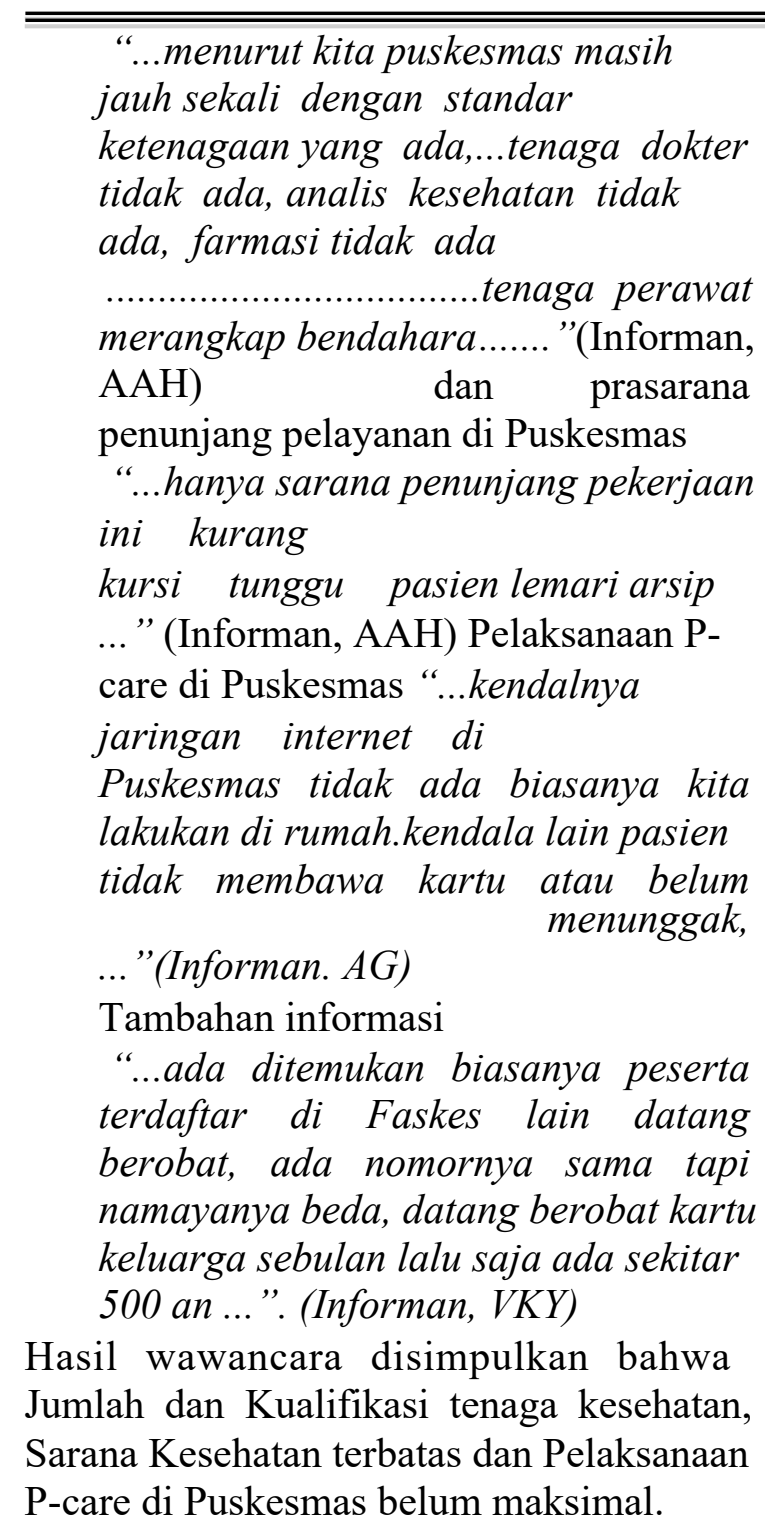

Proses Implementasi Jaminan Kesehatan Nasional di Kabupaten Buol Komunikasi antar organisasi,, koordinasi antar organisasi serta sosilaisasi meliputi Dinas Kesehatan, BPJS, Dinsos, Dinas PPKAD, memerlukan satu pemahaman melalui komunikasi antar organisasi sehingga tujuan pelaksanaan yang diharapkan akan tercapai dari hasil wawancara dengan informan sebagai berikut

Mengkomunikasikan program JKN di kabupaten Buol

".....dalam mengkomunikasikan program JKN adanya namanya forum komunikasi secara berkala dilakukan......" (Informan, BS).

Sosialisasi Kepesertaan

“..,,,Sosialisasi belum terlalu intens dilaksanakan di hanya mengacu

pada acara tertentu yang

berhubungan dengan kesehatan

tapi muatanya JKN

kita mengharapkan BPJS turun

bersama ke kecamatan..................."

(Informan, MR).

Mengkoordinasikan pembiayaan PBI

APBD dengan Instansi lain

“.....kebetulan kami ada kesepakatan DidengKaersehstruheholder, pembiyaan..." (Informan, MR).

Koordinasi perpindahan Peserta FKTP calon Penerima Bantuan iuran PBI

“

Peserta memilih Faskes dengan dekat dengan domisili mereka, lalu kita pindahkan..." (Informan, BS.

Hasil wawancara disimpulkan bahwa komunikasikan, sosialisasi dan koordinasi program JKN di kabupaten Buol telah dilaksanakan namun belum maksimal.

Kondisi Sosial Ekonomi dan Politik apakah terpengaruh oleh pelaksanaan kebijakan, seberapa menonjol isu terkait kebijakan, sejauh mana kelompok kepentingan swasta dimobilisasi untuk mendukung kebijakan dari hasil wawancara dengan informan sebagai berikut ;

Manfaatnya dirasakan oleh masyarakat dengan adanya JKN

“...saya kalau saki-saki panas sadiki

ke puskesmas atau sama ses...tidak dibayar juga

kalau saya sakit tidak ada yang ba urus itu kebun..." (Informan KDR).

Penggalian potensi-potensi swasta dalam mendukung pelaksanakaan JKN

“.....sebernanya kita akan mengadakan pemotongan pembiayaan kepada kontraktor...tapi kontraktor keberatan alasan mereka karyawan bukan karyawan tetap...sampai sekarang belum terealisasi..." (informan MR)

Dukungan biaya operasional dalam pelaksanaan JKN 
pelaksanaann JKN tidak ada sama sekali, karena itu sudah menjadi tanggung jawab kita mau tidak mau kita laksanakan "(Informan, SLT).

Hasil wawancara disimpulkan bahwa dengan adanya JKN masyarakat lebih produktif namun penggalian potensipotensi swasta dalam mendukung pelaksanakaan JKN belum dilaksanakan dan dukungan biaya operasional dalam pelaksanaan JKN belum memadai.

Karateristik Badan Pelaksana yang terdiri dari Dinas Kesehatan, BPJS, Dinsos, kontrol hierarkis pelaksana yang lebih tinggi bupati maupun Sekretaris Daerah, Hubungan Badan Pelaksana Kompetensi Dinas Kesehatan, BPJS, Dinsos, seberapa vital organisasi pelaksana kebijakan, dari hasil wawancara dengan informan sebagai berikut ;

“...pelaksanaan JKN kurang lebih 6 instansi, masing-mersingg insmaxiguitus kesehatan, ada mengurus masalah sosial pokonya beda la...itu sala satu penghambat......" (Informan, MR).

“...tidak di aplikasikan apa yang menjadi tujuan program ....karna beda instansi tidak mungkin intervensi mereka " (Informan, BS).

Hasil wawancara disimpulkan bahwa katareristik masing Dinas menjadi penghambat dalam pelaksanaan JKN

Sikap para pelaksanan di puskesmas atau FKTP dalam pelaksanaan Jaminan Kesehatan Nasional di Kabupaten Buol dari hasil wawancara dengan informan sebagai berikut ;

“...pasien yang datang ke Puskesmas tidak mempunyai kartu tetap kita layani... kan kita dihitung berdasarkan kapitasi

(Informan, IT).

Sistim rujukan Kepesertaa JKN “...merujuk berdasarkan indikasi... dasar 155 penyakit........kalau tidak berdasarkan tersebut tidak akan dirujuk..." (Informan, SP)

Mekanisme pembagian jasa pelayanan antara staf Puskesmas

“...mereka mengeluh katanya...kita yang DIII lebih banyak dari yang SI padahal kita yang langsung bersentuhan dengan pasien..." (Informan,LS)

Tambahan informasi

“...mekanisme sebaiknya diatur yang langsung bersentuhan dengan pasien dia lebih...kan kalau diluar gedung ada juga biayanya..." (Informan, SP).

Hasil wawancara disimpulkan bahwa sikap pelaksana di Puskesmas sangat, baik Sistim rujukan Kepesertaa JKN sesuai dengan mekanisme namun dalam mekanisme pembagian jasa pelayanan antara staf Puskesmas terjadi ketikdak puasan antara petugas di Puskesmas

Luaran Kinerja Implementasi Jaminan Kesehatan Nasional terdiri dari indikator Akses bahwa orang-orang bertanggung jawab untuk mengimplementasikan kebijakan atau program mudah dikontak oleh masyarakat yang menjadi kelompok sasaran kebijakan atau program tersebut apabila mereka membutuhkan informasi atau ingin menyampaikan pengaduan Purwanto, E.A (2015) dari hasil wawancara dengan informan sebagai berikut ;

"... tidak ada tempat melapor kalau ada masalah JKN ..tidak kami tidak tahu siapa penanggung jawab di kabupaten...dan tidak ada nomor telpon yang bisa kami hubungi" (Informan, JSM).

Indikator cakupan ini digunakan untuk menilai seberapa besar kelompok sasaran PBI APBN dan PBI APBD yang sudah dapat dijangkauoleh kebijakan publik yang di implementasikan dari hasil wawancara dengan informan sebagai berikut ; 


\begin{tabular}{l}
\hline \hline ".. kami sudah di data dan foto copi \\
KK sudah diberikan untuk \\
mendapat kartu JKN-KIS tapi \\
sampai sekarang tidak ada \\
...................” (Informan DDST) \\
Tambahan Informasi \\
"
\end{tabular}

Kartu JKN KIS ada tapi hanya saya dan istriku dan satu anak yang dapat 3 anak belum dapat kartu JKN

\section{" (Informan BT).}

Bias merupakan indikator yang digunakan untuk menilai apakah pelayanan yang diberikan oleh implementer bias (menyimpang) kepada kelompok masyarakat yang bukan sasaran menjadi sasaran atau kelompok masyarakat dari hasil wawancara dengan informan sebagai berikut ;

\section{"...saya mempunyai 2 kartu yang satu Jamsostek satunya JKNKIS.." ( Informan M).}

Hasil wawancara dan observasi disimpulkan bahwa belum efektif Akses bagi masyarakat yang membutuhkan informasi atau ingin menyampaikan pengaduan, belum semua masyrakat peserta PBI tercakup JKN dan adanya Bias atau penyimpangan dalam pelaksanaan JKN di Kabupaten Buol.

\section{PEMBAHASAN}

Penelitian menemukan bahwa Standar Kebijakan dan Sumber Daya dalam Implementasi Jaminan Kesehatan Nasional di Kabupaten Buol ditinjau dari Aspek Peraturan/Regulasi yang dikeluarkan pemerintah Kabupaten Buol maupun Regulasi dari Navionteriareguhasi mertg̀dallin mencukupi namun tujuan regulasi dibuat terjadi pemahaman berbeda untuk mendukung tiga aspek meliputi perluasan cakupan kepesertaan, peningkatan kualitas pelayanan kesehatan serta penegakan regulasi namun pelaksanaan regulasi di tingkat Puskesmas yang dikeluarkan oleh kementerian Kesehatan dapat mendorong pelaksanaan pelayanan kesehatan di FKTP agar lebih bermutu dan menjadi standar acuan pelaksanaan JKN di Puskesmas.

Standar Kebijakan dan Sumber Daya dalam Implementasi Jaminan Kesehatan Nasional di Kabupaten Buol ditinjau dari Aspek Kepesertaan ditemukan terjadi Perbedaan data kepesertaan PBI APBD antara BPJS Kabupaten Buol sebanyak 36.363, Dinas Sosial Kabupaten sebanyak 2,923 Peserta dan Dinas Kesehatan Kabupaten 31,611. Hasil temuan bahwa PBI APBD tidak mempunyai indikator dalam menetukan kepesertaan Penerima Bantuan Iuran (PBI), untuk menentukan kepesertaan berdasarkan pekerjaan peserta apabila petani dan nelayan termasuk Penerima Bantuan Iuran demikian juga hasil observasi dilapangan ditemukan sala satu penduduk mengganti pekerjaan di wirasuasta ke Petani untuk mendapatkan kartu JKN-KIS.

Peserta PBI APBN untuk menverfikasi menelusuri melalui kartu $\mathrm{KK}$ dan diberi keterangan peserta yang meninggal, pindah sedangkan hasil observasi dilapangan Kartu keluarga di kabupaten Buol sedangkan FKTP di yang tertera di Kartu KIS di kabupaten lain dan peserta belum merubah kartu KK sehingga peserta yang meninggal masih tercantum dalam kartu KK tersebut serta adanya perbedaan antara kartu KK dengan penerimaan KIS.

Permensos No 05 tahun 2016 pelaksanaan PP nomor 762015 tentang perubahan PP nomor 101 tahun 2012 tentang penerima bantuan iuran bahwa verifikasi dan validasi perubahan data PBI JKN pengecakan langsung kerumah tangga atau keluarga dan melalui musyawarah desa.

Pendistribusian kartu Kepesertaan JKN-KIS Pihak BPJS menunjuk pihak ketiga dimana Pihak Ketiga yang ditunjuk adalah Dinas Sosial sebagai pendistribusi, pihak pendistribusi tidak langsung kepeserta tapi melalui aparat desa sehinga ditemukan masih ada sebagian kartu berada di Desa. 
Standar Kebijakan dan Sumber Daya dalam Implementasi Jaminan Kesehatan Nasional di Kabupaten Buol ditinjau dari Pembiayaan Dinas Kesehatan sebagai pelaksana Pembiayaan Peserta PBI APBD ditemukan terjadi kenaikan pembiayaan PBI APBD sebesar $80 \%$ dari tahun sebelumnya asumsi dengan terjadi kenaikan pembiayaan terjadi peningkatan masyarakat miskin dari hasil wawancara pembiayaan PBI APBD telah mencukupi. Namun hasil temuan dalam penelitian ini bahwa Dana APBD di Dinas Kesehatan sebagian terserap ke Pembiayaan PBI APBD secara tidak langsung mengurangi porsi pembiayaan program lain dari hasil wawancara kepala Dinas PPKAD Kab. Buol sebagai tim TPAD strategi yang dilakukan dalam mencukupi Pembiayaan Kepesertaan PBI APBD adalah mengurangi belanja yang tidak perlu, seperti perjalanan dinas Pegawai, atau kegiatan yang tidak langsung bersentuhan dengan masyarakat.

Standar Kebijakan dan Sumber Daya dalam Implementasi Jaminan Kesehatan Nasional di Kabupaten Buol ditinjau dari Pelayanan Kesehatan di FKTP ditemukan bahwa Tenaga kesehatan sebagai Pegawai Negeri Sipil di Puskesmas Lakea, Momunu dan Gadung sangat kurang tenaga kesehatan di dominasi pegawai honor, kontrak, dan sukarela karena tidak adanya tenaga adminisrtrasi dan pekarya di puskesmas sehingga tenaga kesehatan merangkap bendahara/pengelolah JKN.

Prasarana di puskesmas di Kabupaten Buol di bangun tahun 2015 dan 2016 dan telah sesuai dengan ketentuan permenkes nomor 75 tahun 2014, sedangkan sarana sebagai penunjang pelaksanan pelayanan masih kurang dari segi peralatan medis dan non medis telah memamadai hanya terkendala dari bahan habis pakai dari dari dana kapitasi Puskesmas mengadakan bahan-bahan habis pakai dan dana belanja barang dan jasa, kegiatan promotif dilaksanakan di alihkan ke pembiayaan Dana BOK (Bantuan Operasional Puskesmas) dalam pelaksanaan P-Care (Primary Care) di Puskesmas masih banyak kendala yang dihadapi dari segi jaringan internet, dari segi kepesertaan petugas menemukan masih banyak kartu yang ganda, ada yang memiliki kartu KIS tapi non aktif, pasien terdaftar di faskes lain, pasien tidak mempunyai kartu KIS paling banyak.

Proses Implementasi Jaminan Kesehatan Nasional di Kabupaten Buol dalam penelitian inidi temukan bahwa komunikasi dilakukan secara periode melibatkan SKPD di Kabupaten Buol dengan BPJS yang terbentuk dalam forum Komunikasi dalam forum tersebut masing-masing memaparkan tentang pelaksanaan program, pelaksanaan sosialisasi telah dilakukan di tingkat kabupaten namun tidak efektif di tingkat kecamatan masing-masing SKPD dan BPJS tidak bersama-sama dalam melakukan sosialisasi serta sosilaisasi tersebut tidak intens dilaksanakan dan belum menyentuh masyarakat sebagai peserta JKN, koordinasi pembiayaan peserta PBI APBD dilaksanakan dalam penentuan Jumlah Peserta dan perpindahan peserta di FKTP belum melibatkan Dinas terkait.

Kondisi Sosial Ekonomi dan Politik masyarakat berdasarkan data BPS Kabupaten Buol (2017) bahwa pertumbuhan ekonomi melambat dipengaruhi oleh menurunnya produktifitas hasil pertanian, kehutanan dan perikanan, namun menurut Jonnadi, A., Amar, S., \& Aimon, H. (2012) bahwa pengaruh tersebut tidak terlalu besar dalam penurunan kemiskinan sehingga program JKN sangat menonjol di masyarakat, dimana JKN sangat besar manfaatnya dirasakan oleh masyarakat dengan adanya JKN masyarakat lebih produktif sebagaimana penelitian yang dilakukan oleh Widianti, V., \& Rahman, A. Z. (2017). Kebijakan masyarakat kepada yang tidak mampu dapat memanfaatkan fasilitas kesehatan dan berobat menjadi peserta jaminan kesehatan tanpa di pungut biaya peserta tersebut dapat mengalokasikan uangnya untuk memenuhi kebutuhan pokok selain kesehatan. Situasi politik di Kabupaten Buol cukup kondusif 
adapun penggalian potensi-potensi swasta dalam mendukung pelaksanakaan JKN di Kabupaten Buol belum maksimal, ditemukan pemberi kerja tidak mendaftarkan para pekerjanya untuk mendapatkan Jaminan Kesehatan, Jaminan Kesehatan Para pekerja masih oleh ditanggung oleh pemerintah daerah dengan kata lain bahwa tidak ada pihak swasta di dimobilisasi untuk mendukung pelaksanaan Jaminan Kesehatan Nasional di Kabupaten Buol, sesuai Instruksi Presiden Nomor 8 Tahun 2017 tentang Optimalisasi Pelaksanaan program Jaminan Kesehatan Nasional bahwa bupati berhak memberikan sanksi administrative kepada Pemberi Kerja yang tidak patuh dalam pendaftaran dan pembayaran iuran Peserta JKN.

Dukungan biaya operasional dalam pelaksanaan JKN di Dinas Kesehatan termuat dalam dana DAU seperti operasional monitoring dan evaluasi bagi pengelola JKN bimbingan teknis dan operasional yang lain seperti honor lintas sektor namun berbeda dengan informan dari Dinas Sosial bahwa dukungan dana operasional pelaksanaann JKN tidak dalam anggaran di Dinas tersebut.

Karateristik Badan pelaksana atau organisasi yanng berbeda berperan besar dalam implementasi JKN, Kajian dilaksanakan melihat pemangku kepentingan atau stakeholder di Kabupaten Buol bahwa setiap organisasi berbeda kompotensinya dan berbeda tujuannya maupun visi misi masing-masing, Dinas kesehatan sebagai pembiayaan dan pelayanan kesehatan, Dinas sosial berperan dalam kepesertaan, Dinas catatan sipil menyangkut kependudukan, Dinas Nakertrans menyakut ketenagaan kerjaan dan BPJS sebagai sebagai penjamin kesehatan sehingga apa yang menjadi tujuan dari pelaksanaan JKN tidak tercapai demikian pula dengan kontrol hirarki secara vertikal oleh pejabat Pemda Kabupaten Buol belum maksimal dilakukan kegiatan forum komunikasi dilaksanakan sebatas pertemuan.

Sikap para pelaksanan di Puskesmas atau FKTP dalam kemampuan dan kemauan mereka untuk melaksanakan sistim rujukan berjenjang di Puskesmas sesuai kebijakan yang diatur oleh Kemenkes dan BPJS, dibuktikan dengan presentase rujukan di Puskesmas Lakea Momunu dan Gadung presentase rujukan di bawah $10 \%$ tahun 2017, tidak ada penolakan pada terhadap pasien yang datang di Puskesmas.

Mekanisme pembagian jasa pelayanan antara staf Puskesmas terjadi ketidak puasan para pelaksana atau petugas di Puskesmas dimana yang langsung bersentuhan dengan pasien lebih kecil imbalan jasa diberikan serta jumlah peserta kapitasi yang berubah tidak tetap tidak mempengaruh dalam pelayanan dan pembiyaan Puskesmas. berkaitan dengan pembagian anggaran untuk jasa, penelitian yang dilakukan Maidin Alimin,dkk bahwa terdapat petugas PPK yang menginginkan agar pembagian anggaran untuk jasa didasarkan pada beban kerja, bukan tingkat pendidikan.(Maidin \& Palutturi, 2016).

Penelitian ini menunjukan Luaran Implementasi Jaminan Kesehatan Nasional di Kabupaten Buol bahwa Akses masyarakat untuk melapor masalah kartu JKN-KIS, atau kepesertaan belum optimal serta belum dibentuknya Forum Koordinasi (Posko Pemantauan dan Penanganan Pengaduan Distribusi KIS) P3DKIS Tingkat Kabupaten/Kota dan belum dibentuknya Tim Safeguarding JKN Dinas Kesehatan guna menagani keluhan-keluhan yang diterima tentang masalah JKN dari masyarakat atau fasilitas kesehatan, adapun kotak pengaduan yang ada di Puskesmas milik BPJS tidak di fungsikan.

Cakupan Kepesertaan Jaminan Kesehatan Nasional dari PBI PBI APBD 8.808 Jiwa sedangkan kelompok sasaran yang telah di jangkau dengan mendapatkan kartu JKN-KIS sebanyak 31.611 peserta dari data tersebut disimpulkan bahwa ada kelebihan kepesertaan PBI APBD sebanyak 23.106 Jiwa dari observasi dan wawancara ditemukan kelompok sasaran penerima bantuan Iuran belum mendapatkan cakupan 
Kartu JKN-KIS.

Total seluruh kepesertan PBI APBN dan PBI APBD 75.584 peserta namun hasil observasi bahwa pelaksana Program Jaminan Kesehatan tejadi bias (menyimpang) kepada kelompok masyarakat yang bukan menjadi sasaran program bantuan iuran hasil temuan dilapangan Peserta mendapatkan 2 (dua) kartu Jaminan Kesehatan dan pasien yang akan melahirkan disegerakan untuk mendapatkan kartu JKN-KIS serta kartu Jaminan Kesehatan hanya diberikan tanpa melihat keadaan ekonomi kelurga yang menerima hal ini disimpulkan bahwa ada terjadi Bias atau penyimpangan dalam pelaksanaan Jaminan Kesehatan Nasional di Kabupaten Buol.

\section{KESIMPULAN DAN SARAN}

Berdasarkan hasil dan pembahasan Implementasi Jaminan Kesehatan Nasional di Kabupaten Buol dilihat dari data Regulasi, Kepesertaan, Pembiayaan disebabkan karena proses komunikasi antar organisasi kurang efisien dan karateristik masing-masing organisasi menyebabkan kegagalan JKN di Implementasikan sehingga sasaran cakupan kepesertaan terjadi penyimpangan atau Bias.

Implementasi Jaminan Kesehatan Nasional di Kabupaten Buol menjadi efektif serta efisien maka beberapa saran kebijakan yaitu; Segera mungkin melakukan pendataan Masyarakat Miskin dan tidak mampu, Cost sharing pembiayaan PBI APBD dan PBI APBN, Komunikasi dan koordinasi dimaksimalkan guna meminalisir perbedaan jumlah kepesertaan dan pembiayaan JKN dan Memaksimalkan fungsi-fungsi menajemen sehingga karateristik organisasi atau dinas tidak menjadi penghambat dalam implementasi Jaminan Kesehatan Nasional di Kabupaten Buol.

\section{DAFTAR PUSTAKA}

BPS.(2017).Satististik Kesejateraan Rakyat Kabupaten Buol Tahun 2017. Badan Pusat Statististik
Kabupaten Buol

Purwanto,E.A.(.2015). Implentasi Kebijakan Publik Konsep dan Aplikasinya di Indonesia (I Ed. Vol. II). Klitren Lor GK II /15 Jogjakarta: Perbit Gava Media.

Jonnadi, A., Amar, S., \& Aimon, H. (2012). Analisis Pertumbuhan Ekonomi dan Kemiskinan Di Indonesia. Jurnal Kajian Ekonomi, 1(1).

Kemensekneg. (2017). Intruksi Presiden Nomor 08 Tahun 2017 Tentang Optimalisasi Pelaksanaan Program Jaminan Kesehatan Nasional Jakarta. 2018

Litawati, H. (2016). Strategi perencanaan jaminan kesehatan semesta Kabupaten Banyuwangi Jurnal Ilmiah Administrasi Publik (JIAP), JIAP Vol. 2, No. 1, pp 46-56, 2016.

Maidin, A., \& Palutturi, S. (2016). Kajian Implementasi Jaminan Kesehatan Nasional Lintas Provinsi (Sulawesi Selatan, Sulawesi Tenggara, Sulawesi Barat) Tahun 2014. Jurnal Kebijakan Kesehatan Indonesia, Volume 05 No 03 September 2016 Halaman $96-100$. Puspandari, D. A. (2015). Pengaruh Regulasi Jaminan Kesehatan Nasional Terhadap Pelaksanaan Fungsi UKM (upaya kesehatan masyarakat) Di Puskesmas Ngaglik II Kabupaten Sleman. Universitas Gadjah Mada.

Rukmini, R., Ristrini, R., \& Tumaji, T. (2017). Integrasi Jamkesda dalam JKN bagi PBI di Kota Blitar dan Kota Malang. Buletin Penelitian Sistem Kesehatan, 20(1), 34-42. Setyawati, D., Suryawati, C., \& Jati, S. P. (2016). Analisis Pemetaan Integrasi Program Jaminan Kesehatan Daerah ke Program Jaminan Kesehatan Nasional di Kabupaten Purbalingga Tahun 


2016-2018. Universitas

Diponegoro Semarang.

Van Meter, D. S., \& Van Horn, C. E. (1975). The policy implementation process: A conceptual framework. Administration \& Society, 6(4), 445-488.

Widianti, V., \& Rahman, A. Z. (2017). Implementasi Peraturan Gubernur Provinsi DKI Jakarta Nomor 123 Tahun 2014 Tentang Kepesertaan Dan Pelayanan Jaminan Kesehatan Di DKI Jakarta. Journal of Public Policy and Management Review, 6(2), 431-440.

Yin, R. K. (2008). Case Study Research Design and Methods (Vol.5):

SAGE Publications,Inc. 